\title{
(NUEVAS) NARRATIVAS Y ESFERA PÚBLICA. ANÁLISIS CUALITATIVO DEL RESCATE DE 33 MINEROS EN CHILE
}

\author{
(NEW) NARRATIVES AND PUBLIC SPHERE. QUALITATIVE \\ ANALYSIS OF THE RESCUE OF 33 MINERS IN CHILE
}

\section{AlBERTO PEDRO LÓPEZ-HERMIDA RUSSO*}

\section{RESUMEN}

La marea de estímulos informativos en la que navegamos actualmente exige que el político -como cualquier líder social-deba competir con innumerables pantallas y datos. El storytelling surge en los últimos años como técnica efectiva para que el mensaje logre conquistar el bien más preciado en esta Economía de la Atención: el tiempo del ciudadano. Este estudio introduce esta herramienta discursiva, sus condiciones y elementos, y por medio de un análisis narrativo-cualitativo se expone su presencia -con aciertos y desaciertos- en el discurso entregado a la opinión pública tras el rescate de los 33 mineros chilenos atrapados a 700 metros de profundidad en agosto de 2010.

Palabras clave: Storytelling, narrativa, Chile, mineros, comunicación, comunicación política.

\section{ABSTRACT}

The overflow of information stimuli we currently browse through requires that politicians -like any social leader- deal with countless screens and data. Storytelling emerged in recent years as an effective technique for a message to conquer the most precious thing in this Economy of Attention: the citizen's time. This study introduces this dis-

* Doctor en Comunicación Pública, Facultad de Comunicación, Universidad de los Andes. Santiago, Chile. Correo electrónico: alhr@uandes.cl, @albertopedro 
cursive tool, its conditions and elements. Through a narrative-qualitative analysis, we explain its presence -with strengths and weaknesses-in a speech delivered to the public after the rescue of 33 Chilean miners trapped 700m deep in August 2010.

Keywords: Storytelling, narrative, Chile, 33 miners, communication, political communication.

Recibido: 13.09.14. Aceptado: 05.12.14.

\section{RELATOS CONFIABLES PARA UN ESCENARIO SEMBRADO DE DUDAS}

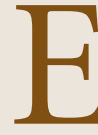

N EL ESCENARIO COMUNICACIONAL actual, con la inmensidad de estímulos sensoriales, las mayores exigencias de los ciudadanos y el desmedido bombardeo informativo, es un hecho que el político, el empresario, el publicista, el profesor y cualquier líder social no lo tiene fácil para comunicar su mensaje en aras de ganar la confianza, o al menos la atención, del receptor. Indudablemente hoy es más sencillo distribuir un contenido; pero, paradójicamente, es mucho más difícil lograr que éste sea recibido e interpretado correctamente .

Así, el storytelling (re)aparece como herramienta de comunicación en la esfera pública, con altas potencialidades para recuperar esa confianza perdida. Su objetivo principal es que el mensaje se repita y afecte en primer término las emociones de las personas a través de la narración de un relato que, en definitiva, involucra al receptor haciéndole ver como propia una realidad que, sólo racionalmente, podría parecer ajena.

"La sociedad del infoentretenimiento es contexto de nuevos horizontes de expectativa en los individuos, que, además, demuestran una escasa credibilidad en las instituciones y los partidos políticos, y se enfrentan con graves problemas en la vida cotidiana (desempleo, inseguridad, violencia)" (Martini, 2000, p. 20). En este contexto Luntz aconseja que el lenguaje a usar en los relatos sea personal y humano para gatillar en los receptores un recuerdo emocional. En esta línea el mismo autor cita a Warren Beatty, quien en una ocasión le dijo que "la gente olvidará lo que dijiste, pero nunca va a olvidar cómo la hiciste sentir" (Luntz, 2007, p. 18).

Se entiende así la importancia y el interés por las emociones y el papel de "puerta de entrada discursiva" de éstas para afectar la confianza del receptor. Charlotte Beers afirma en Salmon que actualmente vivimos en un universo cargado de éstas. "Es algo tan emocional como los terroristas, 
como la violencia y la religión y las cuestiones espirituales... Por eso hoy, a menudo, nos tornamos no sólo hacia los hechos, las palabras y aquel que hablaba a la cámara, sino también hacia libros, fotos, que vehiculan historias" (Salmon, 2008, p. 206).

Ante esta realidad "lo importante ya no es el debate de ideas, sino la regulación de las emociones" (cfr. Salmon en Cantor, 2008). De este modo, se empieza a valorar la "inteligencia emocional" de las personas y, entonces, los políticos, medios de comunicación, entre otros, utilizan los cinco sentidos para incorporarlos dentro de sus historias y, así, lograr hacer llegar su mensaje de manera simple, clara y comprensible.

En este escenario la clave está en el hecho de que "la carga emocional de los relatos capta mejor nuestra atención que la simple información, haciendo que aprehendamos el sentido de los acontecimientos de una manera más rápida y más profunda que los mensajes asépticamente informativos" (Núñez, 2008, p. 16).

De hecho, como explican Arroyas y Pérez, "la confianza no se gana a través del convencimiento por los hechos, sino como un premio a la empatía despertada por alguien que no nos miente (o todavía no lo ha hecho)" (2009, p. 5).

Es por todo esto que el storytelling ha surgido como la alternativa a todo tipo de discurso racional que, guste o no, ya no atrae la confianza y despierta la sospecha de los individuos. Y no sólo eso, el arte de contar relatos también nace como una opción para, como dice Núñez, fomentar la cohesión de un grupo, en una sociedad donde la individualización está reinando. El storytelling permite que se cree un relato compartido, pues existe en él un concepto que engloba una idea común.

Al final, como dice Anette Simmons, el mejor relato gana. Pues el usuario del relato - por su tiempo escaso- va a elegir una historia entre las que ofrecen diariamente miles de emisores. Y "si tu relato no es una fuente de sentido para tu audiencia potencial, fracasará ante la avalancha de otros relatos, mediáticos o sociales que compiten por hacerlo" (Núñez, 2008, p. 31).

Núñez define el storytelling como "una herramienta de comunicación estructurada en una secuencia de acontecimientos que apelan a nuestros sentidos y emociones. Al exponer un conflicto, revela una verdad que aporta sentido a nuestras vidas" (2008, p. 17).

Un relato "no es un cuento para niños, ni un chiste. Tampoco es una narración entretenida. Ni siquiera es una mera leyenda. Un relato tiene algo de sagrado, porque es una verdad universal cargada de emociones y de sensaciones. Como tal verdad universal, una narración es capaz de aportar 
sentido a nuestras vidas, arrojar luz sobre algún misterio del mundo que nos rodea" (Núñez, 2008, p. 15).

Salmon, en tanto, aporta una visión más crítica pero igual de valiosa, definiendo el storytelling como un "arma de distracción masiva" que apela directamente a lo emocional. Como explica Miguel Roig, "se trata de una manera distinta de gestionar los relatos para utilizar la narración como una manera de convencer y movilizar la opinión" (Salmon, 2008, p. 13).

"La propia estructura del relato (con un narrador y una historia que tiene personajes, un principio, un nudo y un desenlace o final que ilustra una verdad, una enseñanza que todos asimilamos a partir de nuestras propias experiencias) consigue, de entrada, captar mejor nuestra atención y que retengamos de manera clara ideas, imágenes y sensaciones que hacen del relato algo vivo y lleno de matices y significados" (Gutiérrez-Rubí, 2009).

Un buen relato, dice Simmons, afecta los cinco sentidos de las personas. "Tu meta al contar historias es para que tu auditor vea, escuche, huela, sienta y saboree los elementos de tu historia, necesario para que sus imaginaciones los lleven ahî" (Simmons, 2006).

A través de esta técnica se pretende transmitir ideas que generen confianza. Esto sólo se logra a medida que el relato narrado sea lo suficientemente atractivo para que se vaya difundiendo entre los mismos individuos. "El individuo no acude a la escena pública con el afán de comprender o debatir asuntos comunes, sino para satisfacer una necesidad natural de interconectarse para aliviar su aislamiento" (Arroyas y Pérez, 2009, p. 3).

Una manera de hacer esto es a través del storytelling. El ser humano cuenta su historia y escucha la de otros como una forma de buscar su identidad y evita, sobre todo en una sociedad como la actual, todo tipo de alocución puramente racional que lo aleja de esa búsqueda personal. "Las realidades que verdaderamente nos interesan no son aquellas susceptibles de ser demostradas matemáticamente: son identidades, personas con vida interior, con intimidad, que crecen desde dentro, es decir, sujeto" (Terrasa en Barrera y Jimeno, 1991, p. 506).

Es por esto que el ciudadano tiende a escuchar los relatos que cuentan otros, con el fin de encontrar en él algo que se asocie con el suyo. No obstante, para conseguir la atención del individuo hace falta algo más que contar una simple historia, pues hoy existe un entorno saturado de mensajes frente al cual el ciudadano reacciona hostilmente. Núñez define esta situación como la Economía de la Atención, donde el tiempo del ser humano es escaso y ha perdido interés por las estadísticas y los argumentos que sólo apelan a la razón. Por lo tanto, el político, los medios de comunicación, 
los empresarios, los psicólogos, profesores, entre otros, se enfrentan a una realidad donde atraer el interés de los individuos es tarea difícil.

\section{CONDICIONES Y ELEMENTOS DEL RELATO CONFIABLE}

Esbozado lo que es el storytelling, se debe tener en cuenta las condiciones para que éste pueda comenzar a bosquejarse y los elementos que debe incluir dicho cuadro (cfr. Simmons, 2006; Lakoff, 2007; Luntz, 2007; Gutiérrez-Rubí, 2009; Schwarz, 2008; Giansante, 2009; Hosein, 2012). Se da por sentado que al querer narrar una historia determinada ya se cuenta con un escenario, un protagonista y un guión.

El éxito de la narración está condicionado por la coherencia espaciotemporal que exista entre el escenario, el protagonista y el guión, que juntos deben tener una linealidad que sostenga el interés del espectador. De lo contrario, la historia no sólo pierde la atención (que de algún modo es recuperable), sino que se pierde del todo la credibilidad y genera sospecha.

Por tanto, "el relato no es una retahíla de palabras, ideas o datos. El relato es una historia que cobra vida y es efectivo cuando transmite, evoca, comunica, emociona, moviliza, seduce, identifica, compromete y convence desde la veracidad de lo que sentimos como auténtico" (Gutiérrez-Rubí, 2009, p. 28).

Cumplidas estas condiciones, un relato debería incluir, de modo más o menos explícito, según sea el caso, ocho elementos, considerando la enorme cantidad de soportes en los que los más variados storytellers pueden narrar una historia. Estos elementos son los siguientes:

a. Relato propiamente tal, que hace referencia concretamente a ese elemento que vale la pena compartir para conquistar la atención de la audiencia en un escenario saturado de mensajes. Como ya se ha indicado, la historia apunta directamente a las emociones del receptor, quien se ve explícita o implícitamente interpelado.

b. Marco o encuadre que es el escenario conceptual, espacial y temporal en el que el relato se expone. Incluye esos marcos simbólicos de los que habla Lakoff, compartidos y consensuados a lo largo de la historia como creencias universales, la evocación de imágenes e ideas que viven en nuestro subconsciente y que despiertan en cada uno emociones y experiencias vitales.

c. Ritmo u orden determinado de exposición que asegure un desarrollo 
estructurado que concluya con un efecto claro. También denominado timing, debe traducirse en la resonancia coral -musical- entre el espectador y el lenguaje en el que el narrador entrega la historia, evitando así que grupos de receptores perciban la narración de modo desordenado.

d. Una red de contagio resulta clave para que el objetivo del relato se cumpla y llegue a la mayor cantidad de receptores posible. Si bien a la gente le gusta escuchar historias y tiende a repetirlas directamente, en el escenario actual ese contagio se ha visto reforzado por nuevos medios de comunicación como Internet, permitiendo, así, que más gente reciba el mensaje por medio de la viralización.

e. Incluir una metáfora permite entender un concepto concreto generalmente ajeno o desconocido gracias a la referencia a otro de naturaleza más abstracta pero universalmente conocido. Al ser, en definitiva, el fondo del relato, resulta fundamental a la hora de buscar, por ejemplo, un vínculo global entre varios relatos particulares.

f. La presencia de un mito dentro del relato genera ineludiblemente movilización por parte del oyente, derrotando la pasividad temerosa desprendida de un escenario tormentoso. Contar con un referente formal que organiza el cosmos de la narración transmite en definitiva un modelo de conducta (Campbell, 1959).

g. El rito de todo relato, en tanto, consiste en cómo se constituye ese modelo mitológico enunciado, lo que generalmente se traduce en la vinculación ceremonial, a veces sagrada, con el receptor.

h. Por último, el relato debe hacer referencia a un arquetipo o imagen mental rápidamente evocable, que permita la rápida comprensión como la familiarización con el relato y la permanencia del mismo.

\section{LOS 33 Y UN RESPIRO DE APROBACIÓN Y CONFIANZA}

Un rápido repaso a los índices de popularidad en los dos primeros años de gobierno del Presidente chileno Sebastián Piñera (2010-2014) muestra un escenario nada alentador, más aún considerando que su predecesora, $\mathrm{Mi}$ chelle Bachelet, dejó la Presidencia con una popularidad que sobrepasaba el $80 \%$.

Más allá de las razones políticas que estas cifras pudieran esconder, la era Piñera guarda un componente bastante interesante para quienes inves- 
tigan la Comunicación, particularmente la Política. Pese a un crecimiento económico promedio de un 5\%, con índices inéditos de pleno empleo y en un escenario mundial bastante convulso, no logra transmitir las bondades de esos índices.

Los análisis políticos como académicos suelen concordar que parte de este fenómeno encuentra su génesis en una falta de estrategia de comunicación, que en ocasiones ha llevado a cometer errores que, a fin de cuentas, terminan por desaprovechar instancias de transmisión de valor por medio de, precisamente, un relato (Funk, 2011).

Pese a lo anterior, tanto en aprobación como en transmisión de confianza se ve un pico llamativo el mes de octubre de 2010, no tan pronunciado y menos sostenido que el pico de desaprobación y desconfianza de agosto de 2011. Mientras éste responde al conflicto estudiantil y la radicalización de las marchas por las calles de Santiago, aquellas cifras positivas del segundo semestre de 2010 tienen un solo responsable: el rescate de los 33 mineros atrapados en la mina San José.

Como diría días después Francesc Pujol, analizando precisamente el impacto de lo realizado en el norte de Chile, "la propia dinámica del rescate y su espectacular éxito final ha propiciado una historia con un interés mediático inusitado" (2010, p. 3 ) y Piñera fue consciente de ello.

El 5 de agosto de 2010 un derrumbe dejó atrapados a 33 mineros a más de 700 metros de profundidad en un yacimiento cercano a Copiapó, a 810 kilómetros al norte de Santiago.

Luego de desechar un posible rescate con un equipo humano tras un nuevo derrumbe, se inició la perforación e introducción de sondas con el fin de alcanzar el lugar en el que, tentativamente, pudieran estar los atrapados. Sin embargo, la precariedad de los planos entregados por al empresa dueña del yacimiento hacía de esta estrategia algo a todas luces inefectivo.

El entonces ministro de Minería, Laurence Golborne, dirigía la operación desde el lugar y hacía eco a la insistencia del Presidente Piñera por encontrar a cualquier precio a los mineros.

El 22 de agosto una de las sondas logró "romper fondo" y, al regresar a la superficie, fueron encontrados indicios de vida en el taladro: manchas de pintura roja, cartas y un trozo de papel que el mismo Presidente Piñera mostraría al país y que rezaba: "Estamos bien en el refugio los 33".

El país entero estalló en celebración y, con el paso de los días, se fueron mostrando videos y audios desde las profundidades, con mensajes, experiencias y la entonación permanente del Himno Nacional de Chile. 
Se dio inicio a la Operación San Lorenzo, que consistía en perforar hasta el refugio y enviar una cápsula que pudiera extraer uno a uno a los atrapados. Sólo así, el 12 de octubre y después de 69 días bajo tierra, fueron rescatados con vida todos los mineros, en medio de una fiesta nacional y la atención mediática de todo el planeta (cfr. Pujol, 2010) (Información detallada del accidente y el rescate: $B B C$ http://goo.gl/xAP6R, El País, http:// goo.gl/HdDG y El Mercurio, http://goo.gl/Jo7LK).

El análisis que se desarrolla a continuación es una aproximación narrativa de corte cualitativo de la galería de imágenes que, tras el rescate, el propio Gobierno de Chile subió a su cuenta oficial de Flickr (hoy deshabilitada tras el cambio de gobierno, aunque visitable en http://goo.gl/PpzJl3). Además, el análisis discursivo utilizado para buscar los elementos del storytelling se sostiene en el documental encargado por el Ejecutivo -dirigido por Reinaldo Sepúlveda y Eduardo Bertrán- que se transformó en el regalo oficial a toda visita oficial a La Moneda (Dicho documental está disponible íntegramente en http://goo.gl/etVK9y).

Aplicando un método de análisis narrativo se examinan los elementos ya señalados del storytelling en la galería de imágenes y el documental, que hacen las veces de objeto de estudio. Se entiende dicho conjunto audiovisual como una unidad narrativa, susceptible de análisis en cuanto "organiza la información, eventos y experiencias que fluyen a través del tiempo, proporcionando una línea argumental o trama desde un punto de vista particular” (Neuman, 2006, pp. 474 y ss. Cfr. López-Hermida y Vargas, 2013 y López-Hermida e Ibieta, 2013).

Por cierto, no es finalidad de este análisis valorar el actuar que rodearon esas horas y menos dar alguna consideración sobre su necesidad. Sencillamente, el presente análisis busca reflejar el uso de una herramienta concreta que forma parte importante de la comunicación política actual. Sólo es el punto de partida desde el que luego podrá debatirse su uso oportuno, ético y políticamente efectivo.

\section{STORYTELLING BAJO TIERRA}

Al igual que el 27 de febrero de 2010, el 12 de octubre de ese mismo año quedará grabado en la historia de Chile. La primera fecha será recordada como el día en el que un sismo de 8.8 grados Richter sacudió al país, segui- 
do de un tsunami que arrasó, con especial violencia en la costa sur del país, con las vidas y bienes de centenares de chilenos.

La segunda fecha, si bien también se enmarca en una tragedia que conmovió al país entero, quedó grabada por su desenlace -no pasó a engrosar la lista de accidentes mortales en la faena minera- y, en especial, por el alcance que tuvo espacial y temporalmente.

El relato propiamente tal no puede dejar indiferente a nadie. Una vez que se encuentra la prueba de vida la historia de supervivencia tiene un atractivo ni siquiera superado por la ficción (inevitable la comparación con "El Gran Carnaval" de Billy Wilder). Una epopeya preñada de 33 biografías.

La riqueza de la narración queda en evidencia en escritos como el del periodista Francisco Perejil de El País:

En la historia de Chile acaban de entrar 33 hombres humildes. Uno es el líder indiscutible; otro es su mano derecha, el capataz discreto que prefiere grabar con la cámara a sus compañeros antes que darse a conocer al resto del país; otro no puede evitar quebrarse cuando saluda a su gente, a pesar de que pretende transmitir una imagen de fuerza; el mayor, a sus 63 años, es hijo, nieto y hermano de mineros y lleva desde los 12 en las minas; el menor tiene $19 \mathrm{y}$, como algunos de sus compañeros, nunca había pisado un yacimiento; uno se destapa como un excelente periodista presentador del resto de sus compañeros; otro ejerce de enfermero; hay un guía espiritual que les lee la Biblia evangélica; un inmigrante boliviano sin padres; un minero que va escribiendo todo lo que les aconteció desde aquel 5 de agosto en que el cerro de la mina San José se les vino encima; otro que fue jugador de primera división y compartió honores con Iván Zamorano. La mitad de ellos vivían de la zona donde se encuentra la mina y otros tenían que viajar más de 12 horas en los días de descanso para reencontrarse con sus familias (Perejil, 2010 http://goo. gl/ydNQ0T).

El marco o encuadre de la historia resulta, trágicamente, perfecto. Un refugio minero a cientos de metros bajo tierra resulta ser un escenario ciertamente ideal a la hora de querer contar una historia. Espacialmente, el relato es bastante susceptible a ser controlado, como de hecho lo fue a la hora del rescate, al emitirse sólo una señal oficial.

Así, cientos de medios de comunicación podían apostar por relatos paralelos -la historia de las familias, de los rescatistas, del campamento-, pero siempre girando en torno a un marco central, rígido, controlado. 


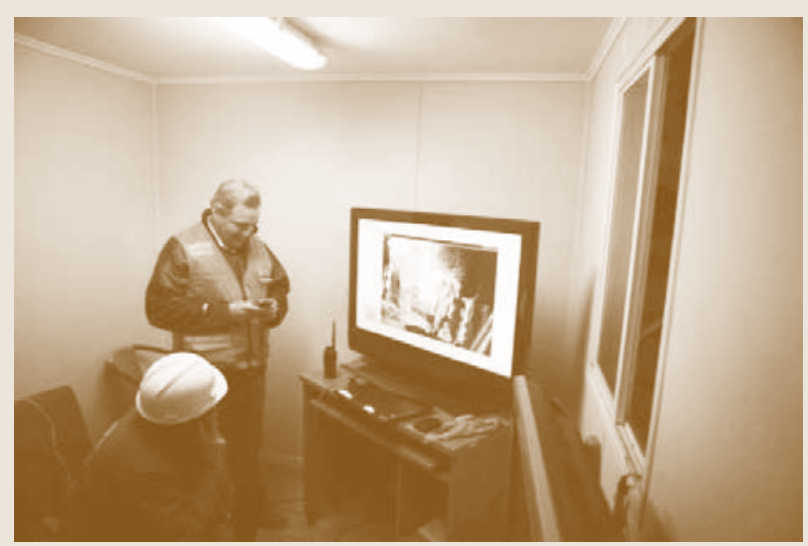

El gobierno dispuso una señal oficial para transmitir imágenes, en especial, del rescate. El marco central de la historia no salía de esas escenas obscuras que venían del refugio. Fuente: Flickr Gobierno de Chile (http://flic.kr/s/aHsjsoqAuq).

Este mismo control espacial iba de la mano del control temporal, lo que permitía un ritmo altamente supervisable en su armonía como en su difusión. Una vez recibidas las señales de vida, tanto fuera como dentro del refugio comenzó a seguirse una rutina rítmica de ejercicios, maniobras, comunicación y entrega de víveres y/o desechos.

Además, la propia operación de rescate tuvo un ritmo dado por las etapas mismas de la maniobra -anclaje, perforación, rotura, etc.- y que permitían a las autoridades ir insinuando fechas estimadas de cada una, disipando, en algo, la ansiedad mediática.

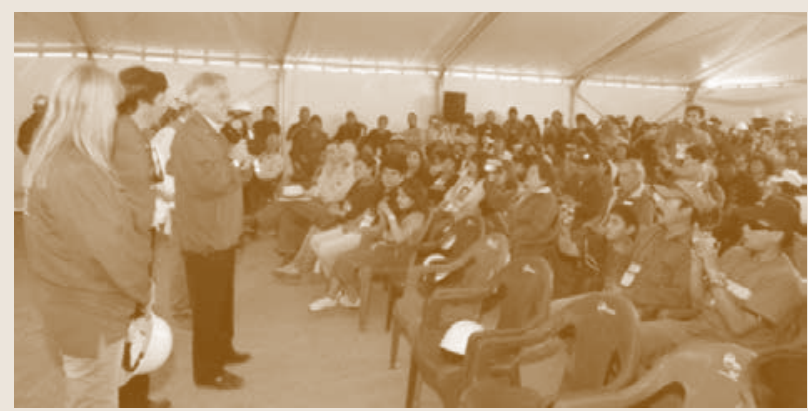

El propio Piñera u otra autoridad informaban periódicamente a los familiares los avances en las tareas de rescate. Fuente: Flickr Gobierno de Chile (http://flic.kr/s/aHsjsoqAuq) 
La red de contagio con la que contó el rescate fue inédita. Quizás convenga concentrar la vista en aquel trozo de papel que los atrapados lograron enviar como prueba de vida y que, en el sentido usado por Gladwell (2000), fue el punto de inflexión (tipping point) entre la repercusión que pudo tener otro-accidente-minero-más y el inicio del rescate de 33 personas atrapadas con vida.

Efectivamente, cuando el Presidente Piñera dio a conocer el "Estamos bien en el refugio los 33" la historia estalló en medios nacionales e internacionales y, desde luego, en las redes sociales. Los chilenos salieron esa misma tarde a las plazas e intersecciones del país a las que se suele ir únicamente cuando se logra algún triunfo deportivo o electoral.

El diario El Mercurio dejó de lado su rígida maqueta para reemplazar el titular del periódico con una imagen del mensaje original y no hubo medio nacional que no enviara inmediatamente a algún reportero al lugar mismo.

Ya para el rescate propiamente tal el interés fue intensamente global. Más de 2.000 periodistas de todo el mundo se apostaron a un costado de la mina y las grandes cadenas -incluida Al Jazeera- transmitieron en directo las 24 horas que duró la operación.

Las audiencias estallaron, calculándose más de 1.000 millones de espectadores en el mundo. Durante el rescate, FoxNews superó los 7 millones, $\mathrm{BBC}$ los 6 millones y CNN rozó los 3 millones, cuotas sólo alcanzadas previamente por un evento noticioso el día de la elección de Barack Obama como Presidente en 2008.

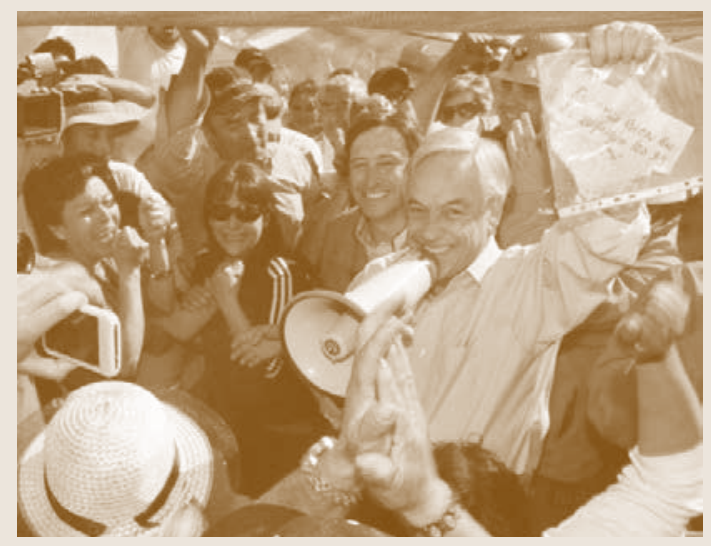

El Presidente Sebastián Piñera da a conocer al país las pruebas de vida enviadas por los mineros atrapados. Entre ellas el trozo de papel con el mensaje "Estamos bien en el refugio los 33". Fuente: Flickr Gobierno de Chile (http://flic.kr/s/aHsjsoqAuq). 
En Internet, el evento se viralizó rápidamente por los motores de búsqueda (600 millones de búsquedas explícitas al tema en Google entre el 12 y el 15 de ese mes) y las redes sociales, acaparando las menciones en Twitter (104 mil tweets del tema por hora y 6 de los 10 trending topics vinculados al suceso), Facebook (500 estados referidos al rescate por minuto en Chile y más de 1.200 en los Estados Unidos) y Youtube (16 mil videos etiquetados durante la operación).

Además, el humor y el ingenio aparecieron rápidamente. En Twitter fueron trending topics \#silosminerosfueranargentinos, \#silosminerosfueranvenezolanos y \#silosminerosfueranmexicanos, con los que se destacaban lo pintoresco de un rescate de esa envergadura en los respectivos países.

Durante el rescate, el sencillo juego web "Los33" alcanzó 45 mil visitas (http://www.root33.cl/casos/campanas/juego-los-33/) y, como alternativa, el sitio "bajemosa33" invitaba a elegir candidatos a ser enviados a la cueva, señalando que "tenemos la cápsula. Tenemos un espacio vacío a 700 metros. Es ahora o nunca".

Impulsado indudablemente por la red de contagio, comenzó a acuñarse un mito que fue central en este episodio de la historia nacional, pero que luego comenzó a extenderse hacia otras instancias.

"The chilean way" pasó a ser el slogan no-oficial más extendido del país sudamericano, en un intento de resumir la seriedad, perseverancia y sacrificio que se encarnaría en el carácter nacional.

Siempre teñida por el periodo de dictadura militar que dirigió al país entre 1973 y 1989, la imagen país no vivía un estallido positivo tan evidente desde la Exposición Universal de Sevilla, en 1992, en el que el inédito traslado de un iceberg desde la Antártica hasta la Península Ibérica logró que el país consolidara, junto a su ya reconocida faceta de seriedad económica, una imagen de tremenda riqueza geo-cultural.

El 2010 Chile celebraba el Bicentenario del inicio de su independencia y este suceso vino a poner al país, precisamente mientras celebraba su nacimiento, en el centro de la noticia, con la atención permanente de 2.000 periodistas venidos de todo el mundo y una fuerza comunicacional que los expertos comparan con una campaña de 2.000 millones de dólares.

"The chilean way" pasó a ser el sinónimo de confianza y argumento recurrente en reuniones oficiales como en las redes sociales. 


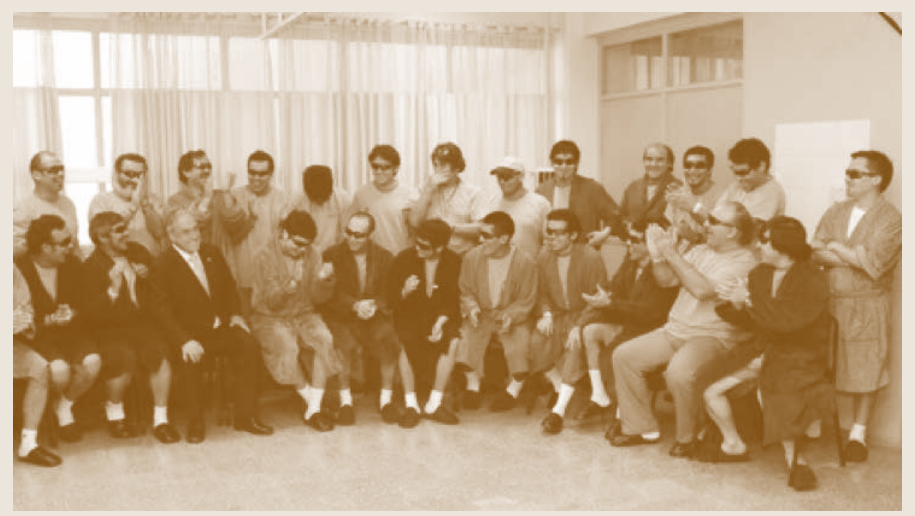

La perseverancia y el trabajo duro pasaron a tener como lema "The chilean way", marca que se empezó a ocupar oficial y extraoficialmente como muestra de confianza. Fuente: Flickr Gobierno de Chile (http://flic.kr/s/ aHsjsoqAuq).

El rito que envolvió al rescate fue tan interesante como colorido. Enmarcado en una solemnidad profesional propia de los mineros y que respetaba protocolos como la participación de pirquineros, mineros profesionales, dueños de la mina y autoridades políticas, quizás encuentre su punto máximo en el momento en el que Luis Urzúa, jefe del accidentado turno y por decisión propia último rescatado, hace entrega oficial del turno al Presidente de Chile, Sebastián Piñera, para que él disponga qué hacer con la mina.

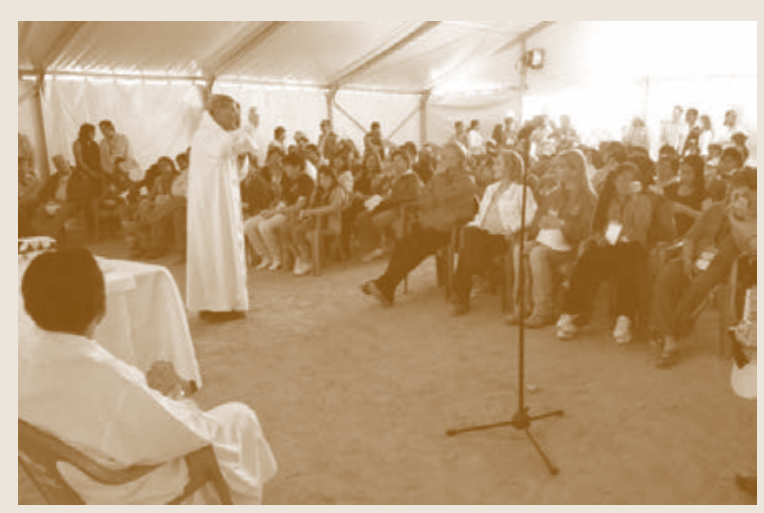

El Presidente Sebastián Piñera en oficio religioso en mina San José. Fuente: Flickr Gobierno de Chile. 
Ese rito, lleno de emociones, fue condimentado fuertemente por la permanente entonación del Himno Nacional y el canto de plegarias de carácter religioso. De hecho, esos días, el campamento fue un punto de encuentro de rituales cristianos, evangélicos, protestantes, indígenas y cabalísticos que hacían del Campamento Esperanza un inédito punto de ritual ecuménico, en torno a la operación San Lorenzo, patrono de los mineros.

De modo paralelo a estos ritos, la metáfora que emerge con fuerza del rescate es la del "re-nacimiento", la "segunda oportunidad" y hasta del "nuevo bautizo" al que se vieron expuestos no sólo los 33 atrapados, sino también sus familiares y amigos.

Desde las cartas extraídas el primer día hasta los testimonios de todos los protagonistas una vez terminada la operación, los relatos están entretejidos de peticiones de perdón, promesas de mejora y agradecimiento a la autoridad terrenal y trascendente.

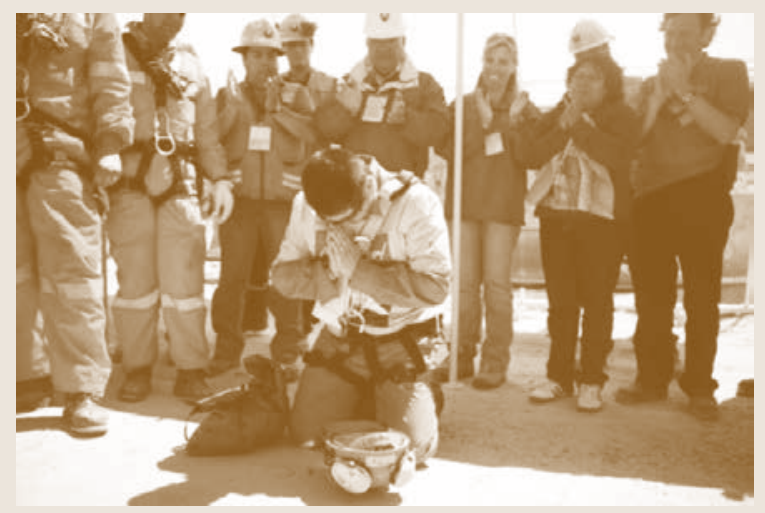

Esteban Rojas luego de salir a la superficie. Grafica segunda oportunidad. Fuente: Flickr Gobierno de Chile (http://flic.kr/s/ aHsjsoqAuq).

Para terminar, el arquetipo que se desprende del rescate de los 33 tiene un paralelo suficientemente claro en el eje locura/cordura de don Quijote de la Mancha y Sancho Panza.

Efectivamente, la obstinación del Presidente Piñera por doblarle la mano al destino y negarse a reconocer cualquier pronóstico que no fuera el de encontrar a los mineros fue permanentemente ponderada por la racionalidad del ministro de Minería, Laurence Golborne, al punto de ser él quien, incluso con lágrimas, debía dar las noticias más "realistas" de cada etapa de rescate. 


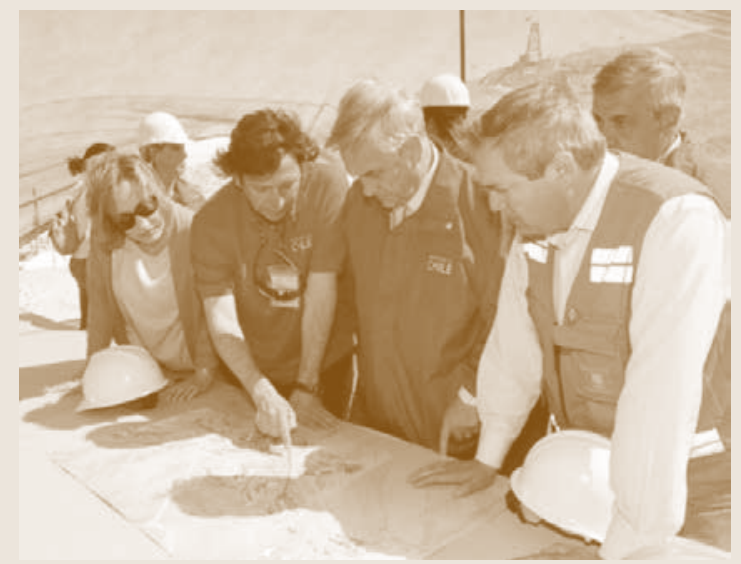

El Presidente Sebastián Piñera y el ministro de Minería Laurence Golborne oficiaron papeles complementarios de racionalidad e impulsividad. Fuente: Flickr Gobierno de Chile (http://flic.kr/s/aHsjsoqAuq).

\section{EL PROBLEMA DEL CIERRE... ¿RETORNO DE LA DESCONFIANZA?}

Dentro de las características de todo relato, el cierre de la historia resulta clave, particularmente en una época en la que las historias suelen continuar total o parcialmente su avance por los canales abiertos como las redes sociales (Miller, 2008).

En ese sentido, el storytelling político -como cualquier tipo de relato institucional actual- debe procurar cerrarse, entendiendo que el cierre, en un escenario sólidamente democrático, de fuerte desafección política y bajo el ritmo trepidante y emocional de las redes sociales, no necesariamente equivale a terminarla.

Tal como un padre inicia el relato a sus hijos antes de dormir con un "Había una vez...", procura terminar de contar la historia con un "colorín colorado", el cierre llamativo del volumen del que se leía y el apagar las luces. Este cierre no evitará que los hijos se queden susurrando detalles o comentando pasajes y menos que al día siguiente especulen sobre cómo puede o debe continuar el relato.

En la política actual -si no en la política de siempre- este cierre es fundamental, pues pone claridad respecto del inicio y término de la participación del storyteller. Otra cosa es lo que de esa historia principal pueda luego desprenderse. 
El caso de la muerte de Osama bin Laden es patente. El Presidente Obama logró discursiva y gráficamente poner fin a un capítulo puntual de la historia de los Estados Unidos. El storyteller central -el mismo Obamapone el punto final al suceso y logra que artículos, películas, documentales y el incesante clamor 2.0 no sean más que añadidos que, para bien o para mal, no afectan al relato central de ese 2 de mayo de 2011 (López-Hermida y Vargas, 2013).

En el caso del rescate de los 33 mineros, tanto el rito de la entrega del turno de parte de Luis Urzúa como la instalación de una placa que sentenciaba el futuro de la mina San José fueron dos instancias perfectas para que el relato quedara oficialmente cerrado.

Además de la necesidad narrativa, estratégicamente era necesario concluir la historia porque a partir de entonces al menos 33 relatos comenzarían a desarrollarse con bastante autonomía, pero con un origen común que, aún abierto, tendría coletazos en todos los protagonistas.

En este escenario, el Presidente Sebastián Piñera no fue capaz de concluir su narración. En vez del "colorín colorado" aprovechó el inicio de una gira el 15 de octubre para contar, recordar y repetir en Francia, Alemania y Gran Bretaña la historia aún fresca; en vez de cerrar el magnífico volumen y dejarlo reposar, el Presidente chileno aprovechó cada encuentro con periodistas, políticos, empresarios y líderes en general, para exhibir el original de la primera señal de vida de los mineros; en vez de apagar la luz y dejar que el mundo disfrutara de una historia ya concluida, el mandatario repartió a empresarios, líderes sociales, presidentes, ministros y reyes sendos trozos de roca extraídos de la caverna.

Gráficamente, el ruego público de la primera dama Cecilia Morel en Gran Bretaña para que Piñera dejase de mostrar el famoso trozo de papel, quizás pase a la historia como la muestra del evidente hostigamiento que, hasta en los protagonistas, genera la falta de cierre.

En ese punto, por ejemplo, "the chilean way" pasó rápidamente a tergiversarse y a ser utilizado con sorna en cada tropiezo que el gobierno cometiera. Habrá que ver, de igual manera, en qué medida todas las especulaciones respecto de la adaptación cinematográfica del rescate afecta a la historia misma, la imagen de los involucrados y del país.

Evidentemente sería apresurado achacar a esta "falta de cierre", por ejemplo, el poco aprovechamiento propagandístico que se le pudo dar a un evento de semejante envergadura en la elección presidencial de finales de 2014, pero algo sí es palpable: la confianza en Piñera y su gobierno por resolver problemas colosales se desplomó 30 puntos en menos de un año, 
con un pobre manejo comunicacional en crisis como la del gas en la región de Magallanes y, desde luego, las movilizaciones estudiantiles.

Queda planteado, pues, que la historia del rescate de "los 33" podría no sólo constituir el mejor momento narrativo de Sebastián Piñera, sino que además aparece como el mejor -entre pocos- aciertos comunicativos de su gobierno. No parece casualidad que, en paralelo, coincida con el mayor nivel de popularidad del Presidente chileno y su más alta transmisión de confianza hacia la ciudadanía.

\section{REFERENCIAS}

Arroyas, E. y Pérez, P. (2009). "El valor de las emociones en los discursos periodísticos del espacio político". En: Actas del I Congreso Internacional de Comunicación Social. Universidad de La Laguna, Tenerife. Disponible en: http://bit.ly/vpP4Qw [fecha de consulta: 30 de septiembre de 2012].

Barrera, C. y Jimeno, M. A. (1991). "La información como relato". Actas de las V Jornadas Internacionales de Ciencias de la Información. Pamplona, España.

Campbell, J. (1959). El héroe de las mil caras. México: Fondo de Cultura Económica.

Cantor, R. (2008). “'Candidatos' y el Storytelling en política”. La Onda Digital, en http://www.laondadigital.com/laonda/LaOnda/426/A4.htm [fecha de consulta: 15 de octubre de 2009].

Funk, R. (2011). "El relato político en el primer año de gobierno de Piñera". Revista de Ciencia Política, 49(2), 151-159.

Giansante, G. (2009). "Érase una vez Silvio. La campaña electoral 2008 de Berlusconi entre Storytelling y Framing". CEU Universidad Cardenal Herrera. Disponible en: http://bit.ly/tVijMz [fecha de consulta: 30 de septiembre de 2012].

Gladwell, M. (2000). La clave del éxito. The Tipping Point. Taurus: Madrid.

Gutiérrez-Rubi, A. (2009). Micropolítica. Ideas para cambiar la comunicación política. Disponible en: http://bit.ly/cQnYeF [fecha de consulta: 30 de septiembre de 2012].

Hosein, H. (2012). Storyteller Uprising. Trust and Persuasion in the Digital Age. Seattle: HRH Media and University Book Store Press.

Lakoff, G. (2007). No pienses en un elefante. Lenguaje y debate politico. Madrid: Complutense.

López-Hermida, A. e Ibieta, N. (2013). "Nuevas narrativas en comunicación de salud: el Storytelling y la conquista emocional del paciente”. Disertaciones, 6(2), artículo X.

López-Hermida, A. y Vargas, J. (2013). "La política relatada: el Storytelling de Barack Obama en el marco de la Operación Gerónimo". Revista Palabra Clave, 16(1): 12-44. 
Luntz, F. (2007). Words that Work: It's Not What You Say, It's What People Hear. New York: Hyperion.

Martini, S. (2000). Periodismo, noticia y noticiabilidad. Bogotá: Norma.

Miller, C. (2008). Digital Storytelling. A Creator's Guide to Interactive Entertainment. Amsterdam: Elsevier.

Neuman, W. L. (2006). Social Research Methods. Qualitative and quantitative approaches. Boston: Pearson.

Núñez, A. (2008). Será mejor que lo cuentes. Los relatos como herramientas de comunicación Storytelling. Barcelona: Empresa Activa.

Pujol, F. (2010). El rescate de los 33 mineros: una epopeya coral. Análisis de impacto mediático y de reputación. Media Reputation Intangibles, Universidad de Navarra, España.

Salmon, C. (2008). Storytelling la máquina de fabricar historias y formatear las mentes. Península.

Schwarz, F. (2008). Mitos, ritos, símbolos: antropología de lo sagrado. Buenos Aires: Biblos.

Simmons, A. (2006). The Story Factory: Inspiration, Influence and Persuasion Through the Art of Storytelling. Nueva York: Basic Books. 